\title{
A New Hybrid Iterative Scheme for Countable Families of Relatively Quasi-Nonexpansive Mappings and System of Equilibrium Problems
}

\author{
Yekini Shehu' ${ }^{1,2}$ \\ ${ }^{1}$ Mathematics Institute, African University of Science and Technology, Abuja, Nigeria \\ ${ }^{2}$ Department of Mathematics, University of Nigeria, Nsukka, Nigeria
}

Correspondence should be addressed to Yekini Shehu, deltanougt2006@yahoo.com

Received 14 February 2011; Accepted 14 April 2011

Academic Editor: Yonghong Yao

Copyright (c) 2011 Yekini Shehu. This is an open access article distributed under the Creative Commons Attribution License, which permits unrestricted use, distribution, and reproduction in any medium, provided the original work is properly cited.

\begin{abstract}
We construct a new iterative scheme by hybrid methods and prove strong convergence theorem for approximation of a common fixed point of two countable families of closed relatively quasinonexpansive mappings which is also a solution to a system of equilibrium problems in a uniformly smooth and strictly convex real Banach space with Kadec-Klee property using the properties of generalized $f$-projection operator. Using this result, we discuss strong convergence theorem concerning variational inequality and convex minimization problems in Banach spaces. Our results extend many known recent results in the literature.
\end{abstract}

\section{Introduction}

Let $E$ be a real Banach space with dual $E^{*}$ and $C$ a nonempty, closed, and convex subset of $E$. A mapping $T: C \rightarrow C$ is called nonexpansive if

$$
\|T x-T y\| \leq\|x-y\|, \quad \forall x, y \in C
$$

A point $x \in C$ is called a fixed point of $T$ if $T x=x$. The set of fixed points of $T$ is denoted by $F(T):=\{x \in C: T x=x\}$.

We denote by $J$ the normalized duality mapping from $E$ to $2^{E^{*}}$ defined by

$$
J(x)=\left\{f \in E^{*}:\langle x, f\rangle=\|x\|^{2}=\|f\|^{2}\right\} .
$$


The following properties of $J$ are well known (the reader can consult [1-3] for more details).

(1) If $E$ is uniformly smooth, then $J$ is norm-to-norm uniformly continuous on each bounded subset of $E$.

(2) $J(x) \neq \emptyset, x \in E$.

(3) If $E$ is reflexive, then $J$ is a mapping from $E$ onto $E^{*}$.

(4) If $E$ is smooth, then $J$ is single valued.

Throughout this paper, we denote by $\phi$ the functional on $E \times E$ defined by

$$
\phi(x, y)=\|x\|^{2}-2\langle x, J(y)\rangle+\|y\|^{2}, \quad \forall x, y \in E .
$$

It is obvious from (1.3) that

$$
(\|x\|-\|y\|)^{2} \leq \phi(x, y) \leq(\|x\|+\|y\|)^{2}, \quad \forall x, y \in E .
$$

Definition 1.1. Let $C$ be a nonempty subset of $E$, and let $T$ be a mapping from $C$ into $E$. A point $p \in C$ is said to be an asymptotic fixed point of $T$ if $C$ contains a sequence $\left\{x_{n}\right\}_{n=0}^{\infty}$ which converges weakly to $p$ and $\lim _{n \rightarrow \infty}\left\|x_{n}-T x_{n}\right\|=0$. The set of asymptotic fixed points of $T$ is denoted by $\widehat{F}(T)$. We say that a mapping $T$ is relatively nonexpansive (see, e.g., [4-9]) if the following conditions are satisfied:

(R1) $F(T) \neq \emptyset$,

(R2) $\phi(p, T x) \leq \phi(p, x)$, for all $x \in C, p \in F(T)$,

(R3) $F(T)=\widehat{F}(T)$.

If $T$ satisfies (R1) and (R2), then $T$ is said to be relatively quasi-nonexpansive. It is easy to see that the class of relatively quasi-nonexpansive mappings contains the class of relatively nonexpansive mappings. Many authors have studied the methods of approximating the fixed points of relatively quasi-nonexpansive mappings (see, e.g., [10-12] and the references cited therein). Clearly, in Hilbert space $H$, relatively quasi-nonexpansive mappings and quasinonexpansive mappings are the same, for $\phi(x, y)=\|x-y\|^{2}$, for all $x, y \in H$, and this implies that

$$
\phi(p, T x) \leq \phi(p, x) \Longleftrightarrow\|T x-p\| \leq\|x-p\|, \quad \forall x \in C, p \in F(T) .
$$

The examples of relatively quasi-nonexpansive mappings are given in [11].

Let $F$ be a bifunction of $C \times C$ into $\mathbb{R}$. The equilibrium problem (see, e.g., [13-25]) is to find $x^{*} \in C$ such that

$$
F\left(x^{*}, y\right) \geq 0,
$$

for all $y \in C$. We will denote the solutions set of (1.6) by $\operatorname{EP}(F)$. Numerous problems in physics, optimization, and economics reduce to find a solution of problem (1.6). The equilibrium problems include fixed point problems, optimization problems, and variational inequality problems as special cases (see, e.g., [26]). 
In [7], Matsushita and Takahashi introduced a hybrid iterative scheme for approximation of fixed points of relatively nonexpansive mapping in a uniformly convex real Banach space which is also uniformly smooth: $x_{0} \in C$,

$$
\begin{gathered}
y_{n}=J^{-1}\left(\alpha_{n} J x_{n}+\left(1-\alpha_{n}\right) J T x_{n}\right), \\
H_{n}=\left\{w \in C: \phi\left(w, y_{n}\right) \leq \phi\left(w, x_{n}\right)\right\}, \\
W_{n}=\left\{w \in C:\left\langle x_{n}-w, J x_{0}-J x_{n}\right\rangle \geq 0\right\}, \\
x_{n+1}=\prod_{H_{n} \cap W_{n}} x_{0}, \quad n \geq 0 .
\end{gathered}
$$

They proved that $\left\{x_{n}\right\}_{n=0}^{\infty}$ converges strongly to $\Pi_{F(T)} x_{0}$, where $F(T) \neq \emptyset$.

In [27], Plubtieng and Ungchittrakool introduced the following hybrid projection algorithm for a pair of relatively nonexpansive mappings: $x_{0} \in C$,

$$
\begin{gathered}
z_{n}=J^{-1}\left(\beta_{n}^{(1)} J x_{n}+\beta_{n}^{(2)} J T x_{n}+\beta_{n}^{(3)} J S x_{n}\right), \\
y_{n}=J^{-1}\left(\alpha_{n} J x_{0}+\left(1-\alpha_{n}\right) J z_{n}\right), \\
C_{n}=\left\{z \in C: \phi\left(z, y_{n}\right) \leq \phi\left(z, x_{n}\right)+\alpha_{n}\left(\left\|x_{0}\right\|^{2}+2\left\langle w, J x_{n}-J x_{0}\right\rangle\right)\right\}, \\
Q_{n}=\left\{z \in C:\left\langle x_{n}-z, J x_{n}-J x_{0}\right\rangle \leq 0\right\}, \\
x_{n+1}=P_{C_{n} \cap Q_{n}} x_{0},
\end{gathered}
$$

where $\left\{\alpha_{n}\right\},\left\{\beta_{n}^{(1)}\right\},\left\{\beta_{n}^{(2)}\right\}$, and $\left\{\beta_{n}^{(3)}\right\}$ are sequences in $(0,1)$ satisfying $\beta_{n}^{(1)}+\beta_{n}^{(2)}+\beta_{n}^{(3)}=1$ and $T$ and $S$ are relatively nonexpansive mappings and $J$ is the single-valued duality mapping on $E$. They proved under the appropriate conditions on the parameters that the sequence $\left\{x_{n}\right\}$ generated by (1.8) converges strongly to a common fixed point of $T$ and $S$.

In [9], Takahashi and Zembayashi introduced the following hybrid iterative scheme for approximation of fixed point of relatively nonexpansive mapping which is also a solution to an equilibrium problem in a uniformly convex real Banach space which is also uniformly smooth: $x_{0} \in C, C_{1}=C, x_{1}=\Pi_{C_{1}} x_{0}$,

$$
\begin{gathered}
y_{n}=J^{-1}\left(\alpha_{n} J x_{n}+\left(1-\alpha_{n}\right) J T x_{n}\right), \\
F\left(u_{n}, y\right)+\frac{1}{r_{n}}\left\langle y-u_{n}, J u_{n}-J y_{n}\right\rangle \geq 0, \quad \forall y \in C, \\
C_{n+1}=\left\{w \in C_{n}: \phi\left(w, u_{n}\right) \leq \phi\left(w, x_{n}\right)\right\}, \\
x_{n+1}=\prod_{C_{n+1}} x_{0}, \quad n \geq 1,
\end{gathered}
$$

where $J$ is the duality mapping on $E$. Then, they proved that $\left\{x_{n}\right\}_{n=0}^{\infty}$ converges strongly to $\Pi_{F} x_{0}$, where $F=\mathrm{EP}(F) \cap F(T) \neq \emptyset$. 
Furthermore, in [28], Qin et al. introduced the following hybrid iterative algorithm for approximation of common fixed point of two countable families of closed relatively quasinonexpansive mappings in a uniformly convex and uniform smooth real Banach space:

$$
\begin{gathered}
z_{i, n}=J^{-1}\left(\beta_{n, i}^{(1)} J x_{n}+\beta_{n, i}^{(2)} J T_{i} x_{n}+\beta_{n, i}^{(3)} J S_{i} x_{n}\right), \\
y_{i, n}=J^{-1}\left(\alpha_{n, i} J x_{0}+\left(1-\alpha_{n, i}\right) J z_{i, n}\right), \\
C_{n, i}=\left\{z \in C: \phi\left(z, y_{i, n}\right) \leq \phi\left(z, x_{n}\right)+\alpha_{n, i}\left(\left\|x_{0}\right\|^{2}+2\left\langle z, J x_{n}-J x_{0}\right\rangle\right\},\right. \\
C_{n}=\bigcap_{i \in I} C_{n, i}, \\
Q_{0}=C, \\
Q_{n}=\left\{z \in Q_{n-1}:\left\langle x_{n}-z, J x_{0}-J x_{n}\right\rangle \geq 0\right\}, \\
x_{n+1}=\prod_{C_{n} \cap Q_{n}} x_{0}, \quad n \geq 0 .
\end{gathered}
$$

They proved that the sequence $\left\{x_{n}\right\}$ converges strongly to a common fixed point of the countable families $\left\{T_{i}\right\}$ and $\left\{S_{i}\right\}$ of closed relatively quasi-nonexpansive mappings in a uniformly convex and uniformly smooth Banach space under some appropriate conditions on $\left\{\beta_{n, i}^{(1)}\right\}$, $\left\{\beta_{n, i}^{(2)}\right\},\left\{\beta_{n, i}^{(3)}\right\}$, and $\left\{\alpha_{n, i}\right\}$.

Recently, Li et al. [29] introduced the following hybrid iterative scheme for approximation of fixed points of a relatively nonexpansive mapping using the properties of generalized $f$-projection operator in a uniformly smooth real Banach space which is also uniformly convex: $x_{0} \in C, C_{0}=C$,

$$
\begin{gathered}
y_{n}=J^{-1}\left(\alpha_{n} J x_{n}+\left(1-\alpha_{n}\right) J T x_{n}\right), \\
C_{n+1}=\left\{w \in C_{n}: G\left(w, J y_{n}\right) \leq G\left(w, J x_{n}\right)\right\}, \\
x_{n+1}=\Pi_{C_{n+1}}^{f} x_{0}, \quad n \geq 0 .
\end{gathered}
$$

They proved a strong convergence theorem for finding an element in the fixed points set of $T$. We remark here that the results of Li et al. [29] extended and improved on the results of Matsushita and Takahashi [7].

Quite recently, motivated by the results of Takahashi and Zembayashi [9], Cholamjiak and Suantai [30] proved the following strong convergence theorem by hybrid iterative scheme for approximation of common fixed point of a countable family of closed relatively quasi-nonexpansive mappings which is also a solution to a system of equilibrium problems in uniformly convex and uniformly smooth Banach space.

Theorem 1.2. Let E be a uniformly convex real Banach space which is also uniformly smooth, and let $C$ be a nonempty, closed, and convex subset of $E$. For each $k=1,2, \ldots, m$, let $F_{k}$ be a bifunction from 
$C \times C$ satisfying (A1)-(A4). Suppose $\left\{T_{i}\right\}_{i=1}^{\infty}$ is an infinitely countable family of closed and relatively quasi-nonexpansive mappings of $C$ into itself such that $\Omega:=\bigcap_{k=1}^{m} \operatorname{EP}\left(F_{k}\right) \cap\left(\bigcap_{i=1}^{\infty} F\left(T_{i}\right)\right) \neq \emptyset$. Suppose $\left\{x_{n}\right\}_{n=0}^{\infty}$ is iteratively generated by $x_{0} \in C, C_{0}=C$,

$$
\begin{gathered}
y_{i, n}=J^{-1}\left(\alpha_{n} J x_{n}+\left(1-\alpha_{n}\right) J T_{i} x_{n}\right), \\
u_{i, n}=T_{r_{m}, n}^{F_{m}} T_{r_{m-1}, n}^{F_{m-1}} \cdots T_{r_{2}, n}^{F_{2}} T_{r_{1}, n}^{F_{1}} y_{i, n}, \\
C_{n+1}=\left\{z \in C_{n}: \sup _{i \geq 1} \phi\left(z, u_{i, n}\right) \leq \phi\left(z, x_{n}\right)\right\}, \\
x_{n+1}=\prod_{C_{n+1}} x_{0}, \quad n \geq 0 .
\end{gathered}
$$

Assume that $\left\{\alpha_{n}\right\}_{n=1}^{\infty}$ and $\left\{r_{k, n}\right\}_{n=1}^{\infty}(k=1,2, \ldots, m)$ are sequences which satisfy the following conditions:

(i) $\lim \sup _{n \rightarrow \infty} \alpha_{n}<1$,

(ii) $\liminf _{n \rightarrow \infty} r_{k, n}>0(k=1,2, \ldots, m)$.

Then, $\left\{x_{n}\right\}_{n=0}^{\infty}$ converges strongly to $\Pi_{\Omega} x_{0}$.

Motivated by the above-mentioned results and the on-going research, it is our purpose in this paper to prove a strong convergence theorem for two countable families of closed relatively quasi-nonexpansive mappings which is also a solution to a system of equilibrium problems in a uniformly smooth and strictly convex real Banach space with Kadec-Klee property using the properties of generalized $f$-projection operator. Our results extend the results of Matsushita and Takahashi [7], Takahashi and Zembayashi [9], Qin et al. [28], Cholamjiak and Suantai [30], Li et al. [29], and many other recent known results in the literature.

\section{Preliminaries}

Let $E$ be a real Banach space. The modulus of smoothness of $E$ is the function $\rho_{E}:[0, \infty) \rightarrow$ $[0, \infty)$ defined by

$$
\rho_{E}(t):=\sup \left\{\frac{1}{2}(\|x+y\|+\|x-y\|)-1:\|x\| \leq 1,\|y\| \leq t\right\} .
$$

$E$ is uniformly smooth if and only if

$$
\lim _{t \rightarrow 0} \frac{\rho_{E}(t)}{t}=0
$$

Let $\operatorname{dim} E \geq 2$. The modulus of convexity of $E$ is the function $\delta_{E}:(0,2] \rightarrow[0,1]$ defined by

$$
\delta_{E}(\epsilon):=\inf \left\{1-\left\|\frac{x+y}{2}\right\|:\|x\|=\|y\|=1 ; \epsilon=\|x-y\|\right\}
$$


$E$ is uniformly convex if, for any $\epsilon \in(0,2]$, there exists a $\delta=\delta(\epsilon)>0$ such that if $x, y \in E$ with $\|x\| \leq 1,\|y\| \leq 1$, and $\|\mathrm{x}-y\| \geq \epsilon$, then $\|(1 / 2)(x+y)\| \leq 1-\delta$. Equivalently, $E$ is uniformly convex if and only if $\delta_{E}(\epsilon)>0$ for all $\epsilon \in(0,2]$. A normed space $E$ is called strictly convex if for all $x, y \in E, x \neq y,\|x\|=\|y\|=1$, we have $\|\lambda x+(1-\lambda) y\|<1$, for all $\lambda \in(0,1)$.

Let $E$ be a smooth, strictly convex, and reflexive real Banach space, and let $C$ be a nonempty, closed, and convex subset of E. Following Alber [31], the generalized projection $\Pi_{C}$ from $E$ onto $C$ is defined by

$$
\Pi_{C}(x):=\arg \min _{y \in C} \phi(y, x), \quad \forall x \in E .
$$

The existence and uniqueness of $\Pi_{C}$ follows from the property of the functional $\phi(x, y)$ and strict monotonicity of the mapping $J$ (see, e.g., $[3,31-34]$ ). If $E$ is a Hilbert space, then $\Pi_{C}$ is the metric projection of $H$ onto $C$.

Next, we recall the concept of generalized $f$-projector operator, together with its properties. Let $G: C \times E^{*} \rightarrow \mathbb{R} \cup\{+\infty\}$ be a functional defined as follows:

$$
G(\xi, \varphi)=\|\xi\|^{2}-2\langle\xi, \varphi\rangle+\|\varphi\|^{2}+2 \rho f(\xi)
$$

where $\xi \in C, \varphi \in E^{*}, \rho$ is a positive number, and $f: C \rightarrow \mathbb{R} \cup\{+\infty\}$ is proper, convex, and lower semicontinuous. From the definitions of $G$ and $f$, it is easy to see the following properties:

(i) $G(\xi, \varphi)$ is convex and continuous with respect to $\varphi$ when $\xi$ is fixed,

(ii) $G(\xi, \varphi)$ is convex and lower semicontinuous with respect to $\xi$ when $\varphi$ is fixed.

Definition 2.1 (see $\mathrm{Wu}$ and Huang [35]). Let $E$ be a real Banach space with its dual $E^{*}$. Let $C$ be a nonempty, closed, and convex subset of $E$. We say that $\Pi_{C}^{f}: E^{*} \rightarrow 2^{C}$ is a generalized $f$-projection operator if

$$
\Pi_{C}^{f} \varphi=\left\{u \in C: G(u, \varphi)=\inf _{\xi \in C} G(\xi, \varphi)\right\}, \quad \forall \varphi \in E^{*}
$$

For the generalized $f$-projection operator, Wu and Huang [35] proved the following theorem basic properties.

Lemma 2.2 (see Wu and Huang [35]). Let E be a real reflexive Banach space with its dual $E^{*}$. Let $C$ be a nonempty, closed, and convex subset of $E$. Then, the following statements hold:

(i) $\Pi_{C}^{f}$ is a nonempty closed convex subset of $C$ for all $\varphi \in E^{*}$,

(ii) if $E$ is smooth, then, for all $\varphi \in E^{*}, x \in \Pi_{C}^{f}$ if and only if

$$
\langle x-y, \varphi-J x\rangle+\rho f(y)-\rho f(x) \geq 0, \quad \forall y \in C,
$$

(iii) if $E$ is strictly convex and $f: C \rightarrow \mathbb{R} \cup\{+\infty\}$ is positive homogeneous (i.e., $f(t x)=t f(x)$ for all $t>0$ such that $t x \in C$ where $x \in C)$, then $\Pi_{C}^{f}$ is a single-valued mapping. 
Fan et al. [36] showed that the condition $f$ is positive homogeneous which appeared in Lemma 2.2 can be removed.

Lemma 2.3 (see Fan et al. [36]). Let E be a real reflexive Banach space with its dual $E^{*}$ and $C$ a nonempty, closed, and convex subset of $E$. Then, if $E$ is strictly convex, then $\Pi_{C}^{f}$ is a single-valued mapping.

Recall that $J$ is a single-valued mapping when $E$ is a smooth Banach space. There exists a unique element $\varphi \in E^{*}$ such that $\varphi=J x$ for each $x \in E$. This substitution in (2.5) gives

$$
G(\xi, J x)=\|\xi\|^{2}-2\langle\xi, J x\rangle+\|x\|^{2}+2 \rho f(\xi) .
$$

Now, we consider the second generalized $f$-projection operator in a Banach space.

Definition 2.4. Let $E$ be a real Banach space and $C$ a nonempty, closed, and convex subset of $E$. We say that $\Pi_{C}^{f}: E \rightarrow 2^{C}$ is a generalized $f$-projection operator if

$$
\Pi_{C}^{f} x=\left\{u \in C: G(u, J x)=\inf _{\xi \in C} G(\xi, J x)\right\}, \quad \forall x \in E
$$

Obviously, the definition of $T: C \rightarrow C$ is a relatively quasi-nonexpansive mapping and is equivalent to

$$
\begin{aligned}
& \left(R^{\prime} 1\right) F(T) \neq \emptyset, \\
& \left(R^{\prime} 2\right) G(p, J T x) \leq G(p, J x), \text { for all } x \in C, p \in F(T) .
\end{aligned}
$$

Lemma 2.5 (see Li et al. [29]). Let E be a Banach space, and let $f: E \rightarrow \mathbb{R} \cup\{+\infty\}$ be a lower semicontinuous convex functional. Then, there exists $x^{*} \in E^{*}$ and $\alpha \in \mathbb{R}$ such that

$$
f(x) \geq\left\langle x, x^{*}\right\rangle+\alpha, \quad \forall x \in E
$$

We know that the following lemmas hold for operator $\Pi_{C}^{f}$.

Lemma 2.6 (see Li et al. [29]). Let C be a nonempty, closed, and convex subset of a smooth and reflexive Banach space $E$. Then, the following statements hold:

(i) $\Pi_{C}^{f} x$ is a nonempty closed and convex subset of $C$ for all $x \in E$,

(ii) for all $x \in E, \widehat{x} \in \Pi_{C}^{f} x$ if and only if

$$
\langle\widehat{x}-y, J x-J \widehat{x}\rangle+\rho f(y)-\rho f(x) \geq 0, \quad \forall y \in C,
$$

(iii) if $E$ is strictly convex, then $\Pi_{C}^{f} x$ is a single-valued mapping.

Lemma 2.7 (see Li et al. [29]). Let $C$ be a nonempty, closed, and convex subset of a smooth and reflexive Banach space E. Let $x \in E$ and $\widehat{x} \in \Pi_{C}^{f} x$. Then,

$$
\phi(y, \widehat{x})+G(\widehat{x}, J x) \leq G(y, J x), \quad \forall y \in C
$$


The fixed points set $F(T)$ of a relatively quasi-nonexpansive mapping is closed and convex as given in the following lemma.

Lemma 2.8 (see Chang et al. [37]). Let $C$ be a nonempty, closed, and convex subset of a uniformly smooth and strictly convex real Banach space E which also has Kadec-Klee property. Let $T$ be a closed relatively quasi-nonexpansive mapping of $C$ into itself. Then, $F(T)$ is closed and convex.

Also, this following lemma will be used in the sequel.

Lemma 2.9 (see Cho et al. [38]). Let $E$ be a uniformly convex real Banach space. For arbitrary $r>0$, let $B_{r}(0):=\{x \in E:\|x\| \leq r\}$ and $\lambda, \mu, \gamma \in[0,1]$ such that $\lambda+\mu+\gamma=1$. Then, there exists a continuous strictly increasing convex function

$$
g:[0,2 r] \longrightarrow \mathbb{R}, g(0)=0
$$

such that, for every $x, y, z \in B_{r}(0)$, the following inequality holds:

$$
\|\lambda x+\mu y+\gamma z\|^{2} \leq \lambda\|x\|^{2}+\mu\|y\|^{2}-\lambda \mu g(\|x-y\|) .
$$

For solving the equilibrium problem for a bifunction $F: C \times C \rightarrow \mathbb{R}$, let us assume that $F$ satisfies the following conditions:

(A1) $F(x, x)=0$ for all $x \in C$,

(A2) $F$ is monotone, that is, $F(x, y)+F(y, x) \leq 0$ for all $x, y \in C$,

(A3) for each $x, y \in C, \lim _{t \rightarrow 0} F(t z+(1-t) x, y) \leq F(x, y)$,

(A4) for each $x \in C, y \mapsto F(x, y)$ is convex and lower semicontinuous.

Lemma 2.10 (see Blum and Oettli [26]). Let $C$ be a nonempty closed convex subset of a smooth, strictly convex, and reflexive Banach space $E$, and let $F$ be a bifunction of $C \times C$ into $\mathbb{R}$ satisfying (A1)-(A4). Let $r>0$ and $x \in E$. Then, there exists $z \in C$ such that

$$
F(z, y)+\frac{1}{r}\langle y-z, J z-J x\rangle \geq 0, \forall y \in K .
$$

Lemma 2.11 (see Takahashi and Zembayashi [39]). Let $C$ be a nonempty closed convex subset of a smooth, strictly convex, and reflexive Banach space $E$. Assume that $F: C \times C \rightarrow \mathbb{R}$ satisfies (A1)-(A4). For $r>0$ and $x \in E$, define a mapping $T_{r}^{F}: E \rightarrow C$ as follows:

$$
T_{r}^{F}(x)=\left\{z \in C: F(z, y)+\frac{1}{r}\langle y-z, J z-J x\rangle \geq 0, \forall y \in C\right\}
$$

for all $z \in E$. Then, the following hold:

(1) $T_{r}^{F}$ is singlevalued,

(2) $T_{r}^{F}$ is firmly nonexpansive-type mapping, that is, for any $x, y \in E$,

$$
\left\langle T_{r}^{F} x-T_{r}^{F} y, J T_{r}^{F} x-J T_{r}^{F} y\right\rangle \leq\left\langle T_{r}^{F} x-T_{r}^{F} y, J x-J y\right\rangle,
$$


(3) $F\left(T_{r}^{F}\right)=\mathrm{EP}(F)$,

(4) $\mathrm{EP}(F)$ is closed and convex.

Lemma 2.12 (see Takahashi and Zembayashi [39]). Let $C$ be a nonempty closed convex subset of a smooth, strictly convex, and reflexive Banach space $E$. Assume that $F: C \times C \rightarrow \mathbb{R}$ satisfies (A1)-(A4), and let $r>0$. Then, for each $x \in E$ and $q \in F\left(T_{r}^{F}\right)$,

$$
\phi\left(q, T_{r}^{F} x\right)+\phi\left(T_{r}^{F} x, x\right) \leq \phi(q, x)
$$

For the rest of this paper, the sequence $\left\{x_{n}\right\}_{n=0}^{\infty}$ converges strongly to $p$ and will be denoted by $x_{n} \rightarrow p$ as $n \rightarrow \infty,\left\{x_{n}\right\}_{n=0}^{\infty}$ converges weakly to $p$ and will be denoted by $x_{n} \rightarrow p$ and we will assume that $\beta_{n, i}^{(1)}, \beta_{n, i}^{(2)}, \beta_{n, i}^{(3)} \in[0,1]$, for all $i=1,2,3, \ldots$ such that $\beta_{n, i}^{(1)}+\beta_{n, i}^{(2)}+\beta_{n, i}^{(3)}=$ 1 , for all $n \geq 0$.

We recall that a Banach space $E$ has Kadec-Klee property if, for any sequence $\left\{x_{n}\right\}_{n=0}^{\infty} \subset E$ and $x \in E$ with $x_{n} \rightarrow x$ and $\left\|x_{n}\right\| \rightarrow\|x\|, x_{n} \rightarrow x$ as $n \rightarrow \infty$. We note that every uniformly convex Banach space has the Kadec-Klee property. For more details on Kadec-Klee property, the reader is referred to $[2,33]$.

Lemma 2.13 (see Li et al. [29]). Let E be a Banach space and $y \in E$. Let $f: E \rightarrow \mathbb{R} \cup\{+\infty\}$ be a proper, convex, and lower semicontinuous mapping with convex domain $D(f)$. If $\left\{x_{n}\right\}$ is a sequence in $D(f)$ such that $x_{n} \rightarrow x \in \operatorname{int}(D(f))$ and $\lim _{n \rightarrow \infty} G\left(x_{n}, J y\right)=G(x, J y)$, then $\lim _{n \rightarrow \infty}\left\|x_{n}\right\|=\|x\|$.

\section{Main Results}

Theorem 3.1. Let $E$ be a uniformly smooth and strictly convex real Banach space which also has Kadec-Klee property. Let $C$ be a nonempty, closed, and convex subset of $E$. For each $k=1,2, \ldots, m$, let $F_{k}$ be a bifunction from $C \times C$ satisfying $(A 1)-(A 4)$. Suppose $\left\{T_{i}\right\}_{i=1}^{\infty}$ and $\left\{S_{i}\right\}_{i=1}^{\infty}$ are two countable families of closed relatively quasi-nonexpansive mappings of $C$ into itself such that $\Omega:=\bigcap_{k=1}^{m} \operatorname{EP}\left(F_{k}\right) \cap$ $\left(\bigcap_{i=1}^{\infty} F\left(T_{i}\right)\right) \cap\left(\bigcap_{i=1}^{\infty} F\left(S_{i}\right)\right) \neq \emptyset$. Let $f: E \rightarrow \mathbb{R}$ be a convex and lower semicontinuous mapping with $C \subset \operatorname{int}(D(f))$, and suppose $\left\{x_{n}\right\}_{n=0}^{\infty}$ is iteratively generated by $x_{0} \in C, C_{1, i}=C, C_{1}=$ $\cap_{i=1}^{\infty} C_{1, i}, x_{1}=\Pi_{C_{1}}^{f} x_{0}$,

$$
\begin{gathered}
z_{n, i}=J^{-1}\left(\beta_{n, i}^{(1)} J x_{n}+\beta_{n, i}^{(2)} J T_{i} x_{n}+\beta_{n, i}^{(3)} J S_{i} x_{n}\right), \\
y_{n, i}=J^{-1}\left(\alpha_{n, i} J x_{n}+\left(1-\alpha_{n, i}\right) J z_{n, i}\right), \\
u_{n, i}=T_{r_{m}, n}^{F_{m}} T_{r_{m-1}, n}^{F_{m-1}} \cdots T_{r_{2}, n}^{F_{2}} T_{r_{1}, n}^{F_{1}} y_{n, i}, \\
C_{n+1, i}=\left\{z \in C_{n, i}: G\left(z, J u_{n, i}\right) \leq G\left(z, J x_{n}\right)\right\}, \\
C_{n+1}=\bigcap_{i=1}^{\infty} C_{n+1, i}, \\
x_{n+1}=\Pi_{C_{n+1}}^{f} x_{0}, \quad n \geq 1,
\end{gathered}
$$


with the conditions

(i) $\lim \inf _{n \rightarrow \infty} \beta_{n, i}^{(1)} \beta_{n, i}^{(2)}>0$,

(ii) $\lim \inf _{n \rightarrow \infty} \beta_{n, i}^{(1)} \beta_{n, i}^{(3)}>0$,

(iii) $0 \leq \alpha_{n, i} \leq \alpha<1$ for some $\alpha \in(0,1)$,

(iv) $\left\{r_{k, n}\right\}_{n=1}^{\infty} \subset(0, \infty)(k=1,2, \ldots, m)$ satisfying $\liminf _{n \rightarrow \infty} r_{k, n}>0(k=1,2, \ldots, m)$.

Then, $\left\{x_{n}\right\}_{n=0}^{\infty}$ converges strongly to $\Pi_{\Omega}^{f} x_{0}$.

Proof. We first show that $C_{n}$, for all $n \geq 1$ is closed and convex. It is obvious that $C_{1, i}=C$ is closed and convex. Suppose $C_{k, i}$ is closed and convex for some $k>1$. For each $z \in C_{k, i}$, we see that $G\left(z, J u_{k, i}\right) \leq G\left(z, J x_{k}\right)$ is equivalent to

$$
2\left(\left\langle z, J x_{k}\right\rangle-\left\langle z, J u_{k, i}\right\rangle\right) \leq\left\|x_{k}\right\|^{2}-\left\|u_{k, i}\right\|^{2}
$$

By the construction of the set $C_{k+1, i}$, we see that $C_{k+1, i}$ is closed and convex. Therefore, $C_{k+1}=$ $\bigcap_{i=1}^{\infty} C_{k+1, i}$ is also closed and convex. Hence, $C_{n}$, for all $n \geq 1$ is closed and convex. $u_{n, i}=\theta_{n}^{m} y_{n, i}$.

By taking $\theta_{n}^{k}=T_{r_{k}, n}^{F_{k}} T_{r_{k-1}, n}^{F_{k-1}} \cdots T_{r_{2}, n}^{F_{2}} T_{r_{1}, n}^{F_{1}}, k=1,2, \ldots, m$ and $\theta_{n}^{0}=I$ for all $n \geq 1$, we obtain

We next show that $\Omega \subset C_{n}$, for all $n \geq 1$. For $n=1$, we have $\Omega \subset C=C_{1}$. Then, for each $x^{*} \in \Omega$, we obtain

$$
\begin{aligned}
G\left(x^{*}, J u_{n, i}\right) & =G\left(x^{*}, J \theta_{n}^{m} y_{n, i}\right) \leq G\left(x^{*}, J y_{n, i}\right) \\
& =G\left(x^{*},\left(\alpha_{n, i} J x_{n}+\left(1-\alpha_{n, i}\right) J z_{n, i}\right)\right) \\
& =\left\|x^{*}\right\|^{2}-2 \alpha_{n, i}\left\langle x^{*}, J x_{n}\right\rangle-2\left(1-\alpha_{n, i}\right)\left\langle x^{*}, J z_{n, i}\right\rangle+\left\|\alpha_{n, i} J x_{n}+\left(1-\alpha_{n, i}\right) J z_{n, i}\right\|^{2}+2 \rho f\left(x^{*}\right) \\
& \leq\left\|x^{*}\right\|^{2}-2 \alpha_{n, i}\left\langle x^{*}, J x_{n}\right\rangle-2\left(1-\alpha_{n, i}\right)\left\langle x^{*}, J z_{n, i}\right\rangle+\alpha_{n, i}\left\|x_{n}\right\|^{2}+\left(1-\alpha_{n, i}\right)\left\|z_{n, i}\right\|^{2}+2 \rho f\left(x^{*}\right) \\
& =\alpha_{n, i} G\left(x^{*}, J x_{n}\right)+\left(1-\alpha_{n, i}\right) G\left(x^{*}, J z_{n, i}\right) \\
& =\alpha_{n, i} G\left(x^{*}, J x_{n}\right)+\left(1-\alpha_{n, i}\right) G\left(x^{*},\left(\beta_{n, i}^{(1)} J x_{n}+\beta_{n, i}^{(2)} J T_{i} x_{n}+\beta_{n, i}^{(3)} J S_{i} x_{n}\right)\right) \\
& \leq \alpha_{n, i} G\left(x^{*}, J x_{n}\right)+\left(1-\alpha_{n, i}\right)\left(\left\|x^{*}\right\|^{2}-2 \beta_{n, i}^{(1)}\left\langle x^{*}, J x_{n}\right\rangle\right. \\
& \left.\quad+\beta_{n, i}^{(2)}\left\langle x_{n, i}^{*}, J T_{i} x_{n}\right\rangle-2 \beta_{n, i}^{(3)}\left\langle x_{i}^{*} x_{n}\left\|^{2}+\beta_{n, i}^{(3)}\right\| S_{i} x_{n}\right\rangle+x_{n} \|^{2}+2 \rho f\left(x_{n, i}^{*}\right)\right) \\
& =\alpha_{n, i} G\left(x^{*}, J x_{n} \|^{2}+\left(1-\alpha_{n, i}\right)\left(\beta_{n, i}^{(1)} G\left(x^{*}, J x_{n}\right)+\beta_{n, i}^{(2)} G\left(x^{*}, J T_{i} x_{n}\right)+\beta_{n, i}^{(3)} G\left(x^{*}, J S_{i} x_{n}\right)\right)\right. \\
\leq & G\left(x^{*}, J x_{n}\right) .
\end{aligned}
$$

So, $x^{*} \in C_{n}$. This implies that $\Omega \subset C_{n}$, for all $n \geq 1$. Therefore, $\left\{x_{n}\right\}$ is well defined. 
We now show that $\lim _{n \rightarrow \infty} G\left(x_{n}, J x_{0}\right)$ exists. Since $f: E \rightarrow \mathbb{R}$ is convex and lower semicontinuous, applying Lemma 2.5 , we see that there exists $u^{*} \in E^{*}$ and $\alpha \in \mathbb{R}$ such that

$$
f(y) \geq\left\langle y, u^{*}\right\rangle+\alpha, \quad \forall y \in E
$$

It follows that

$$
\begin{aligned}
G\left(x_{n}, J x_{0}\right) & =\left\|x_{n}\right\|^{2}-2\left\langle x_{n}, J x_{0}\right\rangle+\left\|x_{0}\right\|^{2}+2 \rho f\left(x_{n}\right) \\
& \geq\left\|x_{n}\right\|^{2}-2\left\langle x_{n}, J x_{0}\right\rangle+\left\|x_{0}\right\|^{2}+2 \rho\left\langle x_{n}, u^{*}\right\rangle+2 \rho \alpha \\
& =\left\|x_{n}\right\|^{2}-2\left\langle x_{n}, J x_{0}-\rho u^{*}\right\rangle+\left\|x_{0}\right\|^{2}+2 \rho \alpha \\
& \geq\left\|x_{n}\right\|^{2}-2\left\|x_{n}\right\|\left\|J x_{0}-\rho u^{*}\right\|+\left\|x_{0}\right\|^{2}+2 \rho \alpha \\
& =\left(\left\|x_{n}\right\|-\left\|J x_{0}-\rho u^{*}\right\|\right)^{2}+\left\|x_{0}\right\|^{2}-\left\|J x_{0}-\rho u^{*}\right\|^{2}+2 \rho \alpha .
\end{aligned}
$$

Since $x_{n}=\Pi_{C_{n}}^{f} x_{0}$, it follows from (3.5) that

$$
G\left(x^{*}, J x_{0}\right) \geq G\left(x_{n}, J x_{0}\right) \geq\left(\left\|x_{n}\right\|-\left\|J x_{0}-\rho u^{*}\right\|\right)^{2}+\left\|x_{0}\right\|^{2}-\left\|J x_{0}-\rho u^{*}\right\|^{2}+2 \rho \alpha
$$

for each $x^{*} \in F$. This implies that $\left\{x_{n}\right\}_{n=0}^{\infty}$ is bounded and so is $\left\{G\left(x_{n}, J x_{0}\right)\right\}_{n=0}^{\infty}$. By the construction of $C_{n}$, we have that $C_{n+1} \subset C_{n}$ and $x_{n+1}=\Pi_{C_{n+1}}^{f} x_{0} \in C_{n}$. It then follows from Lemma 2.7 that

$$
\phi\left(x_{n+1}, x_{n}\right)+G\left(x_{n}, J x_{0}\right) \leq G\left(x_{n+1}, J x_{0}\right)
$$

It is obvious that

$$
\phi\left(x_{n+1}, x_{n}\right) \geq\left(\left\|x_{n+1}\right\|-\left\|x_{n}\right\|\right)^{2} \geq 0
$$

and so $\left\{G\left(x_{n}, J x_{0}\right)\right\}_{n=0}^{\infty}$ is nondecreasing. It follows that the limit of $\left\{G\left(x_{n}, J x_{0}\right)\right\}_{n=0}^{\infty}$ exists.

Now since $\left\{x_{n}\right\}_{n=0}^{\infty}$ is bounded in $C$ and $E$ is reflexive, we may assume that $x_{n} \rightarrow p$, and since $C_{n}$ is closed and convex for each $n \geq 1$, it is easy to see that $p \in C_{n}$ for each $n \geq 1$. Again since $x_{n}=\Pi_{C_{n}}^{f} x_{0}$, from the definition of $\Pi_{C_{n}}^{f}$, we obtain

$$
G\left(x_{n}, J x_{0}\right) \leq G\left(p, J x_{0}\right), \quad \forall n \geq 1
$$

Since

$$
\begin{aligned}
\liminf _{n \rightarrow \infty} G\left(x_{n}, J x_{0}\right) & =\liminf _{n \rightarrow \infty}\left\{\left\|x_{n}\right\|^{2}-2\left\langle x_{n}, J x_{0}\right\rangle+\left\|x_{0}\right\|^{2}+2 \rho f\left(x_{n}\right)\right\} \\
& \geq\|p\|^{2}-2\left\langle p, J x_{0}\right\rangle+\left\|x_{0}\right\|^{2}+2 \rho f(p)=G\left(p, J x_{0}\right),
\end{aligned}
$$


then we obtain

$$
G\left(p, J x_{0}\right) \leq \liminf _{n \rightarrow \infty} G\left(x_{n}, J x_{0}\right) \leq \limsup _{n \rightarrow \infty} G\left(x_{n}, J x_{0}\right) \leq G\left(p, J x_{0}\right) .
$$

This implies that $\lim _{n \rightarrow \infty} G\left(x_{n}, J x_{0}\right)=G\left(p, J x_{0}\right)$. By Lemma 2.13, we obtain $\lim _{n \rightarrow \infty}\left\|x_{n}\right\|=$ $\|p\|$. In view of Kadec-Klee property of $E$, we have that $\lim _{n \rightarrow \infty} x_{n}=p$.

We next show that $p \in \bigcap_{k=1}^{m} \operatorname{EP}\left(F_{k}\right) \cap\left(\bigcap_{i=1}^{\infty} F\left(T_{i}\right)\right) \cap\left(\bigcap_{i=1}^{\infty} F\left(S_{i}\right)\right)$. We first show that $\left.p \in \bigcap_{i=1}^{\infty} F\left(T_{i}\right)\right) \cap\left(\bigcap_{i=1}^{\infty} F\left(S_{i}\right)\right.$. By the fact that $C_{n+1} \subset C_{n}$ and $x_{n+1}=\Pi_{C_{n+1}}^{f} x_{0} \in C_{n}$, we obtain

$$
\phi\left(x_{n+1}, u_{n, i}\right) \leq \phi\left(x_{n+1}, x_{n}\right) .
$$

Now, (3.7) implies that

$$
\phi\left(x_{n+1}, u_{n, i}\right) \leq \phi\left(x_{n+1}, x_{n}\right) \leq G\left(x_{n+1}, J x_{0}\right)-G\left(x_{n}, J x_{0}\right) .
$$

Taking the limit as $n \rightarrow \infty$ in (3.13), we obtain

$$
\lim _{n \rightarrow \infty} \phi\left(x_{n+1}, x_{n}\right)=0
$$

Therefore,

$$
\lim _{n \rightarrow \infty} \phi\left(x_{n+1}, u_{n, i}\right)=0, \quad \forall i \geq 1
$$

It then yields that $\lim _{n \rightarrow \infty}\left(\left\|x_{n+1}\right\|-\left\|u_{n, i}\right\|\right)=0$, for all $i \geq 1$. Since $\lim _{n \rightarrow \infty}\left\|x_{n+1}\right\|=\|p\|$, we have

$$
\lim _{n \rightarrow \infty}\left\|u_{n, i}\right\|=\|p\|, \quad \forall i \geq 1
$$

Hence,

$$
\lim _{n \rightarrow \infty}\left\|J u_{n, i}\right\|=\|J p\|, \quad \forall i \geq 1
$$

This implies that $\left\{\left\|J u_{n, i}\right\|\right\}_{n=0}^{\infty}, i \geq 1$ is bounded in $E^{*}$. Since $E$ is reflexive, and so $E^{*}$ is reflexive, we can then assume that $J u_{n, i} \rightarrow f_{0} \in E^{*}$, for all $i \geq 1$. In view of reflexivity of $E$, we see that $J(E)=E^{*}$. Hence, there exists $x \in E$ such that $J x=f_{0}$. Since

$$
\begin{aligned}
\phi\left(x_{n+1}, u_{n, i}\right) & =\left\|x_{n+1}\right\|^{2}-2\left\langle x_{n+1}, J u_{n, i}\right\rangle+\left\|u_{n, i}\right\|^{2} \\
& =\left\|x_{n+1}\right\|^{2}-2\left\langle x_{n+1}, J u_{n, i}\right\rangle+\left\|J u_{n, i}\right\|^{2},
\end{aligned}
$$


taking the limit inferior of both sides of (3.18) and in view of weak lower semicontinuity of $\|\cdot\|$, we have

$$
\begin{aligned}
0 & \geq\|p\|^{2}-2\left\langle p, f_{0}\right\rangle+\left\|f_{0}\right\|^{2}=\|p\|^{2}-2\langle p, J x\rangle+\|J x\|^{2} \\
& =\|p\|^{2}-2\langle p, J x\rangle+\|x\|^{2}=\phi(p, x)
\end{aligned}
$$

that is, $p=x$. This implies that $f_{0}=J p$ and so $J u_{n, i} \rightarrow J p$, for all $i \geq 1$. It follows from $\lim _{n \rightarrow \infty}\left\|J u_{n, i}\right\|=\|J p\|$, for all $i \geq 1$ and Kadec-Klee property of $E^{*}$ that $J u_{n, i} \rightarrow J p$, for all $i \geq$ 1. Note that $J^{-1}: E^{*} \rightarrow E$ is hemicontinuous; it yields that $u_{n, i} \rightarrow p$, for all $i \geq 1$. It then follows from $\lim _{n \rightarrow \infty}\left\|u_{n, i}\right\|=\|p\|$, for all $i \geq 1$ and Kadec-Klee property of $E$ that $\lim _{n \rightarrow \infty} u_{n, i}=p$, for all $i \geq 1$. Hence,

$$
\lim _{n \rightarrow \infty}\left\|x_{n}-u_{n, i}\right\|=0, \quad \forall i \geq 1
$$

Since $J$ is uniformly norm-to-norm continuous on bounded sets and $\lim _{n \rightarrow \infty}\left\|x_{n}-u_{n, i}\right\|=$ 0 , for all $i \geq 1$, we obtain

$$
\lim _{n \rightarrow \infty}\left\|J x_{n}-J u_{n, i}\right\|=0, \quad \forall i \geq 1
$$

Since $\left\{x_{n}\right\}$ is bounded, so are $\left\{z_{n, i}\right\},\left\{J T_{i} x_{n}\right\}$, and $\left\{J S_{i} x_{n}\right\}$. Also, since $E$ is uniformly smooth, $E^{*}$ is uniformly convex. Then, from Lemma 2.9 , we have

$$
\begin{aligned}
G\left(x^{*}, J u_{n, i}\right) & =G\left(x^{*}, J \theta_{n}^{m} y_{n, i}\right) \leq G\left(x^{*}, J y_{n, i}\right) \\
& =G\left(x^{*},\left(\alpha_{n, i} J x_{n}+\left(1-\alpha_{n, i}\right) J z_{n, i}\right)\right) \\
& =\left\|x^{*}\right\|^{2}-2 \alpha_{n, i}\left\langle x^{*}, J x_{n}\right\rangle-2\left(1-\alpha_{n, i}\right)\left\langle x^{*}, J z_{n, i}\right\rangle+\left\|\alpha_{n, i} J x_{n}+\left(1-\alpha_{n, i}\right) J z_{n, i}\right\|^{2}+2 \rho f\left(x^{*}\right) \\
& \leq\left\|x^{*}\right\|^{2}-2 \alpha_{n, i}\left\langle x^{*}, J x_{n}\right\rangle-2\left(1-\alpha_{n, i}\right)\left\langle x^{*}, J z_{n, i}\right\rangle+\alpha_{n, i}\left\|x_{n}\right\|^{2}+\left(1-\alpha_{n, i}\right)\left\|z_{n, i}\right\|^{2}+2 \rho f\left(x^{*}\right) \\
& =\alpha_{n, i} G\left(x^{*}, J x_{n}\right)+\left(1-\alpha_{n, i}\right) G\left(x^{*}, J z_{n, i}\right) \\
& =\alpha_{n, i} G\left(x^{*}, J x_{n}\right)+\left(1-\alpha_{n, i}\right) G\left(x^{*},\left(\beta_{n, i}^{(1)} J x_{n}+\beta_{n, i}^{(2)} J T_{i} x_{n}+\beta_{n, i}^{(3)} J S_{i} x_{n}\right)\right) \\
& \leq \alpha_{n, i} G\left(x^{*}, J x_{n}\right)+\left(1-\alpha_{n, i}\right)\left(\left\|x^{*}\right\|^{2}-2 \beta_{n, i}^{(1)}\left\langle x^{*}, J x_{n}\right\rangle-2 \beta_{n, i}^{(2)}\left\langle x^{*}, J T_{i} x_{n}\right\rangle\right. \\
& \quad-2 \beta_{n, i}^{(3)}\left\langle x^{*}, J S_{i} x_{n}\right\rangle+\beta_{n, i}^{(1)}\left\|x_{n}\right\|^{2}+\beta_{n, i}^{(2)}\left\|T_{i} x_{n}\right\|^{2}+\beta_{n, i}^{(3)}\left\|S_{i} x_{n}\right\|^{2} \\
& \left.\quad-\beta_{n, i}^{(1)} \beta_{n, i}^{(2)} g\left(\left\|J x_{n}-J T_{i} x_{n}\right\|\right)+2 \rho f\left(x^{*}\right)\right)
\end{aligned}
$$




$$
\begin{aligned}
& =\alpha_{n, i} G\left(x^{*}, J x_{n}\right)+\left(1-\alpha_{n, i}\right)\left(\beta_{n, i}^{(1)} G\left(x^{*}, J x_{n}\right)+\beta_{n, i}^{(2)} G\left(x^{*}, J T_{i} x_{n}\right)\right. \\
& \left.+\beta_{n, i}^{(3)} G\left(x^{*}, J S_{i} x_{n}\right)-\beta_{n, i}^{(1)} \beta_{n, i}^{(2)} g\left(\left\|J x_{n}-J T_{i} x_{n}\right\|\right)\right) \\
& \leq \alpha_{n, i} G\left(x^{*}, J x_{n}\right)+\left(1-\alpha_{n, i}\right)\left(\beta_{n, i}^{(1)} G\left(x^{*}, J x_{n}\right)+\beta_{n, i}^{(2)} G\left(x^{*}, J x_{n}\right)\right. \\
& \left.+\beta_{n, i}^{(3)} G\left(x^{*}, J x_{n}\right)-\beta_{n, i}^{(1)} \beta_{n, i}^{(2)} g\left(\left\|J x_{n}-J T_{i} x_{n}\right\|\right)\right) \\
& =\alpha_{n, i} G\left(x^{*}, x_{n}\right)+\left(1-\alpha_{n, i}\right)\left(G\left(x^{*}, J x_{n}\right)-\beta_{n, i}^{(1)} \beta_{n, i}^{(2)} g\left(\left\|J x_{n}-J T_{i} x_{n}\right\|\right)\right) \\
& \leq G\left(x^{*}, J x_{n}\right)-\left(1-\alpha_{n, i}\right) \beta_{n, i}^{(1)} \beta_{n, i}^{(2)} g\left(\left\|J x_{n}-J T_{i} x_{n}\right\|\right) .
\end{aligned}
$$

It then follows that

$$
\begin{aligned}
(1-\alpha) \beta_{n, i}^{(1)} \beta_{n, i}^{(2)} g\left(\left\|J x_{n}-J T_{i} x_{n}\right\|\right) & \leq\left(1-\alpha_{n, i}\right) \beta_{n, i}^{(1)} \beta_{n, i}^{(2)} g\left(\left\|J x_{n}-J T_{i} x_{n}\right\|\right) \\
& \leq G\left(x^{*}, J x_{n}\right)-G\left(x^{*}, J u_{n, i}\right)
\end{aligned}
$$

But

$$
\begin{aligned}
G\left(x^{*}, J x_{n}\right)-G\left(x^{*}, J u_{n, i}\right) & =\left\|x_{n}\right\|^{2}-\left\|u_{n, i}\right\|^{2}-2\left\langle x^{*}, J x_{n}-J u_{n, i}\right\rangle \\
& \leq\left|\left\|x_{n}\right\|^{2}-\left\|u_{n, i}\right\|^{2}\right|+2\left|\left\langle x^{*}, J x_{n}-J u_{n, i}\right\rangle\right| \\
& \leq \mid\left\|x_{n}\right\|-\left\|u_{n, i}\right\|\left(\left\|x_{n}\right\|+\left\|u_{n, i}\right\|\right)+2\left\|x^{*}\right\|\left\|J x_{n}-J u_{n, i}\right\| \\
& \leq\left\|x_{n}-u_{n, i}\right\|\left(\left\|x_{n}\right\|+\left\|u_{n, i}\right\|\right)+2\left\|x^{*}\right\|\left\|J x_{n}-J u_{n, i}\right\| .
\end{aligned}
$$

From $\lim _{n \rightarrow \infty}\left\|x_{n}-u_{n, i}\right\|=0$ and $\lim _{n \rightarrow \infty}\left\|J x_{n}-J u_{n, i}\right\|=0$, we obtain

$$
G\left(x^{*}, J x_{n}\right)-G\left(x^{*}, J u_{n, i}\right) \longrightarrow 0, \quad n \longrightarrow \infty .
$$

Using the condition $\lim \inf _{n \rightarrow \infty} \beta_{n, i}^{(1)} \beta_{n, i}^{(2)}>0$, we have

$$
\lim _{n \rightarrow \infty} g\left(\left\|J x_{n}-J T_{i} x_{n}\right\|\right)=0, \quad \forall i \geq 1
$$

By property of $g$, we have $\lim _{n \rightarrow \infty}\left\|J x_{n}-J T_{i} x_{n}\right\|=0$, for all $i \geq 1$. Since $J^{-1}$ is also uniformly norm-to-norm continuous on bounded sets, we have

$$
\lim _{n \rightarrow \infty}\left\|x_{n}-T_{i} x_{n}\right\|=0, \quad \forall i \geq 1
$$


Similarly, we can show that

$$
\lim _{n \rightarrow \infty}\left\|x_{n}-S_{i} x_{n}\right\|=0, \quad \forall i \geq 1
$$

Since $x_{n} \rightarrow p$ and $T_{i}, S_{i}$ are closed, we have $p \in\left(\bigcap_{i=1}^{\infty} F\left(T_{i}\right)\right) \cap\left(\bigcap_{i=1}^{\infty} F\left(S_{i}\right)\right)$.

Next, we show that $p \in \bigcap_{k=1}^{m} \operatorname{EP}\left(F_{k}\right)$. Now, by Lemma 2.12, we obtain

$$
\begin{aligned}
\phi\left(u_{n, i}, y_{n, i}\right) & =\phi\left(\theta_{n}^{m} y_{n, i}, y_{n, i}\right) \\
& \leq \phi\left(x^{*}, y_{n, i}\right)-\phi\left(x^{*}, \theta_{n}^{m} y_{n, i}\right) \\
& \leq \phi\left(x^{*}, x_{n}\right)-\phi\left(x^{*}, u_{n, i}\right) \longrightarrow 0, \quad n \longrightarrow \infty
\end{aligned}
$$

It then yields that $\lim _{n \rightarrow \infty}\left(\left\|u_{n, i}\right\|-\left\|y_{n, i}\right\|\right)=0$. Since $\lim _{n \rightarrow \infty}\left\|u_{n, i}\right\|=\|p\|, i \geq 1$, we have

$$
\lim _{n \rightarrow \infty}\left\|y_{n, i}\right\|=\|p\|, \quad i \geq 1
$$

Hence,

$$
\lim _{n \rightarrow \infty}\left\|J y_{n, i}\right\|=\|J p\|, \quad i \geq 1
$$

This implies that $\left\{\left\|J y_{n, i}\right\|\right\}_{n=0}^{\infty}$ is bounded in $E^{*}$. Since $E$ is reflexive, and so $E^{*}$ is reflexive, we can then assume that $J y_{n, i} \rightarrow f_{1} \in E^{*}$. In view of reflexivity of $E$, we see that $J(E)=E^{*}$. Hence, there exists $z \in E$ such that $J z=f_{1}$. Since

$$
\begin{aligned}
\phi\left(u_{n, i}, y_{n, i}\right) & =\left\|u_{n, i}\right\|^{2}-2\left\langle u_{n, i}, J y_{n, i}\right\rangle+\left\|y_{n, i}\right\|^{2} \\
& =\left\|u_{n, i}\right\|^{2}-2\left\langle u_{n, i}, J y_{n, i}\right\rangle+\left\|J y_{n, i}\right\|^{2},
\end{aligned}
$$

taking the limit inferior of both sides of (3.32) and in view of weak lower semicontinuity of $\|\cdot\|$, we have

$$
\begin{aligned}
0 & \geq\|p\|^{2}-2\left\langle p, f_{1}\right\rangle+\left\|f_{1}\right\|^{2}=\|p\|^{2}-2\langle p, J z\rangle+\|J z\|^{2} \\
& =\|p\|^{2}-2\langle p, J z\rangle+\|z\|^{2}=\phi(p, z),
\end{aligned}
$$

that is, $p=z$. This implies that $f_{1}=J p$ and so $J y_{n, i} \rightarrow J p$. It follows from $\lim _{n \rightarrow \infty}\left\|J y_{n, i}\right\|=$ $\|J p\|$ and Kadec-Klee property of $E^{*}$ that $J y_{n, i} \rightarrow J p$. Note that $J^{-1}: E^{*} \rightarrow E$ is hemicontinuous; it yields that $y_{n, i} \rightarrow p$. It then follows from $\lim _{n \rightarrow \infty}\left\|y_{n, i}\right\|=\|p\|$ and KadecKlee property of $E$ that $\lim _{n \rightarrow \infty} y_{n, i}=p, i \geq 1$. By the fact that $\theta_{n}^{k}, k=1,2, \ldots, m$ is relatively nonexpansive and using Lemma 2.12 again, we have that

$$
\begin{aligned}
\phi\left(\theta_{n}^{k} y_{n, i}, y_{n, i}\right) & \leq \phi\left(x^{*}, y_{n, i}\right)-\phi\left(x^{*}, \theta_{n}^{k} y_{n, i}\right) \\
& \leq \phi\left(x^{*}, x_{n}\right)-\phi\left(x^{*}, \theta_{n}^{k} y_{n, i}\right) .
\end{aligned}
$$


Observe that

$$
\begin{aligned}
\phi\left(x^{*}, u_{n, i}\right) & =\phi\left(x^{*}, \theta_{n}^{m} y_{n, i}\right) \\
& =\phi\left(x^{*}, T_{r_{m}, n}^{F_{m}} T_{r_{m-1}, n}^{F_{m-1}} \cdots T_{r_{k}, n}^{F_{k}} T_{r_{k-1}, n}^{F_{k-1}} \cdots T_{r_{2}, n}^{F_{2}} T_{r_{1}, n}^{F_{1}} y_{n, i}\right) \\
& =\phi\left(x^{*}, T_{r_{m}, n}^{F_{m}} T_{r_{m-1}, n}^{F_{m-1}} \cdots \theta_{n}^{k} y_{n, i}\right) \\
& \leq \phi\left(x^{*}, \theta_{n}^{k} y_{n, i}\right) .
\end{aligned}
$$

Using (3.35) in (3.34), we obtain

$$
\phi\left(\theta_{n}^{k} y_{n, i}, y_{n, i}\right) \leq \phi\left(x^{*}, x_{n}\right)-\phi\left(x^{*}, u_{n, i}\right) \longrightarrow 0, \quad n \longrightarrow \infty
$$

It then yields that $\lim _{n \rightarrow \infty}\left(\left\|\theta_{n}^{k} y_{n, i}\right\|-\left\|y_{n, i}\right\|\right)=0$. Since $\lim _{n \rightarrow \infty}\left\|y_{n, i}\right\|=\|p\|$, we have

$$
\lim _{n \rightarrow \infty}\left\|\theta_{n}^{k} y_{n, i}\right\|=\|p\|, \quad k=1,2, \ldots, m
$$

This implies that $\left\{\left\|\theta_{n}^{k} y_{n, i}\right\|\right\}_{n=0}^{\infty}$ is bounded in $E$. Since $E$ is reflexive, we can then assume that $\theta_{n}^{k} y_{n, i} \longrightarrow w \in E$. Since

$$
\begin{aligned}
\phi\left(\theta_{n}^{k} y_{n, i}, y_{n, i}\right) & =\left\|\theta_{n}^{k} y_{n, i}\right\|^{2}-2\left\langle\theta_{n}^{k} y_{n, i}, J y_{n, i}\right\rangle+\left\|y_{n, i}\right\|^{2} \\
& =\left\|\theta_{n}^{k} y_{n, i}\right\|^{2}-2\left\langle\theta_{n}^{k} y_{n, i}, J y_{n, i}\right\rangle+\left\|J y_{n, i}\right\|^{2},
\end{aligned}
$$

taking the limit inferior of both sides of (3.38) and in view of weak lower semicontinuity of $\|\cdot\|$, we have

$$
\begin{aligned}
0 & \geq\|w\|^{2}-2\langle w, J p\rangle+\|p\|^{2}=\|w\|^{2}-2\langle w, J p\rangle+\|J p\|^{2} \\
& =\phi(w, p)
\end{aligned}
$$

that is, $p=w$. This implies that $\theta_{n}^{k} y_{n, i} \rightarrow p$. It follows from $\lim _{n \rightarrow \infty}\left\|\theta_{n}^{k} y_{n, i}\right\|=\|p\|$ and KadecKlee property of $E$ that

$$
\theta_{n}^{k} y_{n, i} \longrightarrow p, \quad n \longrightarrow \infty, k=1,2, \ldots, m
$$

Similarly, $\lim _{n \rightarrow \infty}\left\|p-\theta_{n}^{k-1} y_{n, i}\right\|=0, k=1,2, \ldots, m$. This further implies that

$$
\lim _{n \rightarrow \infty}\left\|\theta_{n}^{k} y_{n, i}-\theta_{n}^{k-1} y_{n, i}\right\|=0, \quad i \geq 1
$$


International Journal of Mathematics and Mathematical Sciences

Also, since $J$ is uniformly norm-to-norm continuous on bounded sets and using (3.41), we obtain

$$
\lim _{n \rightarrow \infty}\left\|J \theta_{n}^{k} y_{n, i}-J \theta_{n}^{k-1} y_{n, i}\right\|=0, \quad i \geq 1
$$

Since $\liminf \operatorname{in}_{n \rightarrow \infty} r_{k, n}>0(k=1,2, \ldots, m)$,

$$
\lim _{n \rightarrow \infty} \frac{\left\|J \theta_{n}^{k} y_{n, i}-J \theta_{n}^{k-1} y_{n, i}\right\|}{r_{k, n}}=0
$$

By Lemma 2.11, we have that for each $k=1,2, \ldots, m$

$$
F_{k}\left(\theta_{n}^{k} y_{n, i}, y\right)+\frac{1}{r_{k, n}}\left\langle y-\theta_{n}^{k} y_{n, i}, J \theta_{n}^{k} y_{n, i}-J \theta_{n}^{k-1} y_{n, i}\right\rangle \geq 0, \quad \forall y \in C
$$

Furthermore, using (A2), we obtain

$$
\frac{1}{r_{k, n}}\left\langle y-\theta_{n}^{k} y_{n, i}, J \theta_{n}^{k} y_{n, i}-J \theta_{n}^{k-1} y_{n, i}\right\rangle \geq F_{k}\left(y, \theta_{n}^{k} y_{n, i}\right)
$$

By (A4), (3.43), and $\theta_{n}^{k} y_{n, i} \rightarrow p$, we have for each $k=1,2, \ldots, m$

$$
F_{k}(y, p) \leq 0, \quad \forall y \in C
$$

For fixed $y \in C$, let $z_{t, y}:=t y+(1-t) p$ for all $t \in(0,1]$. This implies that $z_{t, y} \in C$. This yields that $F_{k}\left(z_{t, y}, p\right) \leq 0$. It follows from (A1) and (A4) that

$$
\begin{aligned}
0 & =F_{k}\left(z_{t, y}, z_{t, y}\right) \leq t F_{k}\left(z_{t, y}, y\right)+(1-t) F_{k}\left(z_{t, y}, p\right) \\
& \leq t F_{k}\left(z_{t, y}, y\right)
\end{aligned}
$$

and hence

$$
0 \leq F_{k}\left(z_{t, y}, y\right)
$$

From condition (A3), we obtain

$$
F_{k}(p, y) \geq 0, \quad \forall y \in C
$$

This implies that $p \in \operatorname{EP}\left(F_{k}\right), k=1,2, \ldots, m$. Thus, $p \in \bigcap_{k=1}^{m} \operatorname{EP}\left(F_{k}\right)$. Hence, we have $p \in \Omega=$ $\bigcap_{k=1}^{m} \operatorname{EP}\left(F_{k}\right) \cap\left(\bigcap_{n=0}^{\infty} F\left(T_{i}\right)\right) \cap\left(\bigcap_{i=1}^{\infty} F\left(S_{i}\right)\right)$. 
Finally, we show that $p=\Pi_{\Omega}^{f} x_{0}$. Since $\Omega=\bigcap_{k=1}^{m} \operatorname{EP}\left(F_{k}\right) \cap\left(\bigcap_{n=0}^{\infty} F\left(T_{i}\right)\right) \cap\left(\bigcap_{i=1}^{\infty} F\left(S_{i}\right)\right)$ is a closed and convex set, from Lemma 2.6, we know that $\Pi_{F}^{f} x_{0}$ is single valued and denote $w=\Pi_{\Omega}^{f} x_{0}$. Since $x_{n}=\Pi_{C_{n}}^{f} x_{0}$ and $w \in \Omega \subset C_{n}$, we have

$$
G\left(x_{n}, J x_{0}\right) \leq G\left(w, J x_{0}\right), \quad \forall n \geq 1 .
$$

We know that $G(\xi, J \varphi)$ is convex and lower semicontinuous with respect to $\xi$ when $\varphi$ is fixed. This implies that

$$
G\left(p, J x_{0}\right) \leq \liminf _{n \rightarrow \infty} G\left(x_{n}, J x_{0}\right) \leq \limsup _{n \rightarrow \infty} G\left(x_{n}, J x_{0}\right) \leq G\left(w, J x_{0}\right) .
$$

From the definition of $\Pi_{\Omega}^{f} x_{0}$ and $p \in \Omega$, we see that $p=w$. This completes the proof.

Take $f(x)=0$ for all $x \in E$ in Theorem 3.1, then $G(\xi, J x)=\phi(\xi, x)$ and $\Pi_{C}^{f} x_{0}=\Pi_{C} x_{0}$. Then we obtain the following corollary.

Corollary 3.2. Let E be a uniformly smooth and strictly convex real Banach space which also has Kadec-Klee property. Let $C$ be a nonempty, closed, and convex subset of $E$. For each $k=1,2, \ldots, m$, let $F_{k}$ be a bifunction from $C \times C$ satisfying $(A 1)-(A 4)$. Suppose $\left\{T_{i}\right\}_{i=1}^{\infty}$ and $\left\{S_{i}\right\}_{i=1}^{\infty}$ are two countable families of closed relatively quasi-nonexpansive mappings of $C$ into itself such that $\Omega:=\bigcap_{k=1}^{m} \operatorname{EP}\left(F_{k}\right) \cap$ $\left(\bigcap_{n=1}^{\infty} F\left(T_{i}\right)\right) \cap\left(\bigcap_{n=1}^{\infty} F\left(S_{i}\right)\right) \neq \emptyset$. Suppose $\left\{x_{n}\right\}_{n=0}^{\infty}$ is iteratively generated by $x_{0} \in C, C_{1, i}=C, C_{1}=$ $\cap_{i=1}^{\infty} C_{1, i}, x_{1}=\prod_{C_{1}} x_{0}$,

$$
\begin{gathered}
z_{n, i}=J^{-1}\left(\beta_{n, i}^{(1)} J x_{n}+\beta_{n, i}^{(2)} J T_{i} x_{n}+\beta_{n, i}^{(3)} J S_{i} x_{n}\right), \\
y_{n, i}=J^{-1}\left(\alpha_{n, i} J x_{n}+\left(1-\alpha_{n, i}\right) J z_{n, i}\right), \\
u_{n, i}=T_{r_{m}, n}^{F_{m}} T_{r_{m-1}, n}^{F_{m-1}} \cdots T_{r_{2}, n}^{F_{2}} T_{r_{1}, n}^{F_{1}} y_{n, i}, \\
C_{n+1, i}=\left\{z \in C_{n, i}: \phi\left(z, u_{n, i}\right) \leq \phi\left(z, x_{n}\right)\right\}, \\
C_{n+1}=\bigcap_{i=1}^{\infty} C_{n+1, i} \\
x_{n+1}=\prod_{C_{n+1}} x_{0}, \quad n \geq 1,
\end{gathered}
$$

with the conditions

(i) $\liminf _{n \rightarrow \infty} \beta_{n, i}^{(1)} \beta_{n, i}^{(2)}>0$,

(ii) $\liminf _{n \rightarrow \infty} \beta_{n, i}^{(1)} \beta_{n, i}^{(3)}>0$,

(iii) $0 \leq \alpha_{n, i} \leq \alpha<1$ for some $\alpha \in(0,1)$,

(iv) $\left\{r_{k, n}\right\}_{n=1}^{\infty} \subset(0, \infty)(k=1,2, \ldots, m)$ satisfying $\liminf _{n \rightarrow \infty} r_{k, n}>0(k=1,2, \ldots, m)$.

Then, $\left\{x_{n}\right\}_{n=0}^{\infty}$ converges strongly to $\Pi_{\Omega} x_{0}$. 
Corollary 3.3 (see Li et al. [29]). Let E be a uniformly convex real Banach space which is also uniformly smooth. Let $C$ be a nonempty, closed, and convex subset of $E$. Suppose $T$ is a relatively nonexpansive mapping of $C$ into itself such that $\Omega:=F(T) \neq \emptyset$. Let $f: E \rightarrow \mathbb{R}$ be a convex and lower semicontinuous mapping with $C \subset \operatorname{int}(D(f))$, and suppose $\left\{x_{n}\right\}_{n=0}^{\infty}$ is iteratively generated by $x_{0} \in C, C_{0}=C$,

$$
\begin{gathered}
y_{n}=J^{-1}\left(\alpha_{n} J x_{n}+\left(1-\alpha_{n}\right) J T x_{n}\right), \\
C_{n+1}=\left\{w \in C_{n}: G\left(w, J y_{n}\right) \leq G\left(w, J x_{n}\right)\right\}, \\
x_{n+1}=\Pi_{C_{n+1}}^{f} x_{0}, \quad n \geq 0 .
\end{gathered}
$$

Suppose $\left\{\alpha_{n}\right\}_{n=1}^{\infty}$ is a sequence in $(0,1)$ such that $\limsup _{n \rightarrow \infty} \alpha_{n}<1$. Then, $\left\{x_{n}\right\}_{n=0}^{\infty}$ converges strongly to $\Pi_{\Omega} x_{0}$.

Corollary 3.4 (see Takahashi and Zembayashi [9]). Let E be a uniformly convex real Banach space which is also uniformly smooth. Let $C$ be a nonempty, closed, and convex subset of $E$. Let $F$ be a bifunction from $C \times C$ satisfying (A1)-(A4). Suppose $T$ is a relatively nonexpansive mapping of $C$ into itself such that $\Omega:=\mathrm{EP}(F) \cap F(T) \neq \emptyset$. Let $\left\{x_{n}\right\}_{n=0}^{\infty}$ be iteratively generated by $x_{0} \in C, C_{1}=C$, $x_{1}=\Pi_{C_{1}} x_{0}$,

$$
\begin{gathered}
y_{n}=J^{-1}\left(\alpha_{n, i} J x_{n}+\left(1-\alpha_{n, i}\right) J T x_{n}\right), \\
F\left(u_{n}, y\right)+\frac{1}{r_{n}}\left\langle y-u_{n}, J u_{n}-J y_{n}\right\rangle \geq 0, \quad \forall y \in C, \\
C_{n+1}=\left\{w \in C_{n}: \phi\left(w, u_{n}\right) \leq \phi\left(w, x_{n}\right)\right\}, \\
x_{n+1}=\Pi_{C_{n+1}} x_{0}, \quad n \geq 1,
\end{gathered}
$$

where $J$ is the duality mapping on E. Suppose $\left\{\alpha_{n, i}\right\}_{n=1}^{\infty}$ is a sequence in $(0,1)$ such that $\liminf _{n \rightarrow \infty} \alpha_{n, i}\left(1-\alpha_{n, i}\right)>0$ and $\left\{r_{n}\right\}_{n=1}^{\infty} \subset(0, \infty)$ satisfying $\liminf _{n \rightarrow \infty} r_{n}>0$. Then, $\left\{x_{n}\right\}_{n=0}^{\infty}$ converges strongly to $\Pi_{\Omega} x_{0}$.

\section{Applications}

Let $A$ be a monotone operator from $C$ into $E^{*}$, the classical variational inequality is to find $x^{*} \in C$ such that

$$
\left\langle y-x, A x^{*}\right\rangle \geq 0, \quad \forall y \in C
$$

The set of solutions of (4.1) is denoted by $\mathrm{VI}(C, A)$.

Let $\varphi: C \rightarrow \mathbb{R}$ be a real-valued function. The convex minimization problem is to find $x^{*} \in C$ such that

$$
\varphi\left(x^{*}\right) \leq \varphi(y), \quad \forall y \in C
$$

The set of solutions of (4.2) is denoted by $\operatorname{CMP}(\varphi)$. 
The following lemmas are special cases of Lemmas 2.8 and Lemma 2.9 of [39].

Lemma 4.1. Let $C$ be a nonempty closed convex subset of a smooth, strictly convex, and reflexive Banach space E. Assume that $A: C \rightarrow E^{*}$ is a continuous and monotone operator. For $r>0$ and $x \in E$, define a mapping $T_{r}^{A}: E \rightarrow C$ as follows:

$$
T_{r}^{A}(x)=\left\{z \in C:\langle A z, y-z\rangle+\frac{1}{r}\langle y-z, J z-J x\rangle \geq 0, \forall y \in C\right\}
$$

Then, the following hold:

(1) $T_{r}^{A}$ is singlevalued,

(2) $F\left(T_{r}^{A}\right)=\mathrm{VI}(C, A)$,

(3) $\operatorname{VI}(C, A)$ is closed and convex,

(4) $\phi\left(q, T_{r}^{A} x\right)+\phi\left(T_{r}^{A} x, x\right) \leq \phi(q, x)$, for all $q \in F\left(T_{r}^{A}\right)$.

Lemma 4.2. Let $C$ be a nonempty closed convex subset of a smooth, strictly convex, and reflexive Banach space E. Assume that $\varphi: C \rightarrow \mathbb{R}$ is lower semicontinuous and convex. For $r>0$ and $x \in E$, define a mapping $T_{r}^{\varphi}: E \rightarrow C$ as follows:

$$
T_{r}^{\varphi}(x)=\left\{z \in C: \varphi(y)+\frac{1}{r}\langle y-z, J z-J x\rangle \geq \varphi(z), \forall y \in C\right\} .
$$

Then, the following hold:

(1) $T_{r}^{\varphi}$ is single valued,

(2) $F\left(T_{r}^{\varphi}\right)=C M P(\varphi)$,

(3) $\operatorname{CMP}(\varphi)$ is closed and convex,

(4) $\phi\left(q, T_{r}^{\varphi} x\right)+\phi\left(T_{r}^{\varphi} x, x\right) \leq \phi(q, x)$, for all $q \in F\left(T_{r}^{\varphi}\right)$.

Then we obtain the following theorems from Theorem 3.1.

Theorem 4.3. Let E be a uniformly smooth and strictly convex real Banach space which also has Kadec-Klee property. Let $C$ be a nonempty, closed, and convex subset of $E$. For each $k=1,2, \ldots, m$, let $A_{k}$ be a continuous and monotone operator from $C$ into $E^{*}$. Suppose $\left\{T_{i}\right\}_{i=1}^{\infty}$ and $\left\{S_{i}\right\}_{i=1}^{\infty}$ are two countable families of closed relatively quasi-nonexpansive mappings of $C$ into itself such that $\Omega:=\bigcap_{k=1}^{m} \operatorname{VI}\left(C, A_{k}\right) \cap\left(\bigcap_{i=1}^{\infty} F\left(T_{i}\right)\right) \cap\left(\bigcap_{i=1}^{\infty} F\left(S_{i}\right)\right) \neq \emptyset$. Let $f: E \rightarrow \mathbb{R}$ be a convex and lower 
semicontinuous mapping with $C \subset \operatorname{int}(D(f))$, and suppose $\left\{x_{n}\right\}_{n=0}^{\infty}$ is iteratively generated by $x_{0} \in C, C_{1, i}=C, C_{1}=\cap_{i=1}^{\infty} C_{1, i}, x_{1}=\Pi_{C_{1}}^{f} x_{0}$,

$$
\begin{gathered}
z_{n, i}=J^{-1}\left(\beta_{n, i}^{(1)} J x_{n}+\beta_{n, i}^{(2)} J T_{i} x_{n}+\beta_{n, i}^{(3)} J S_{i} x_{n}\right), \\
y_{n, i}=J^{-1}\left(\alpha_{n, i} J x_{n}+\left(1-\alpha_{n, i}\right) J z_{n, i}\right), \\
u_{n, i}=T_{r_{m}, n}^{A_{m}} T_{r_{m-1}, n}^{A_{m-1}} \cdots T_{r_{2}, n}^{A_{2}} T_{r_{1}, n}^{A_{1}} y_{n, i}, \\
C_{n+1, i}=\left\{z \in C_{n, i}: G\left(z, J u_{n, i}\right) \leq G\left(z, J x_{n}\right)\right\}, \\
C_{n+1}=\bigcap_{i=1}^{\infty} C_{n+1, i}, \\
x_{n+1}=\Pi_{C_{n+1}}^{f} x_{0}, \quad n \geq 1,
\end{gathered}
$$

with the conditions

(i) $\lim \inf _{n \rightarrow \infty} \beta_{n, i}^{(1)} \beta_{n, i}^{(2)}>0$,

(ii) $\liminf _{n \rightarrow \infty} \beta_{n, i}^{(1)} \beta_{n, i}^{(3)}>0$,

(iii) $0 \leq \alpha_{n, i} \leq \alpha<1$ for some $\alpha \in(0,1)$,

(iv) $\left\{r_{k, n}\right\}_{n=1}^{\infty} \subset(0, \infty)(k=1,2, \ldots, m)$ satisfying $\liminf \inf _{n \rightarrow \infty} r_{k, n}>0(k=1,2, \ldots, m)$.

Then, $\left\{x_{n}\right\}_{n=0}^{\infty}$ converges strongly to $\Pi_{\Omega}^{f} x_{0}$.

Theorem 4.4. Let E be a uniformly smooth and strictly convex real Banach space which also has Kadec-Klee property. Let $C$ be a nonempty, closed, and convex subset of $E$. For each $k=1,2, \ldots, m$, let $\varphi_{k}: C \rightarrow \mathbb{R}$ be lower semicontinuous and convex. Suppose $\left\{T_{i}\right\}_{i=1}^{\infty}$ and $\left\{S_{i}\right\}_{i=1}^{\infty}$ are two countable families of closed relatively quasi-nonexpansive mappings of $C$ into itself such that $\Omega:=$ $\bigcap_{k=1}^{m} C M P\left(\varphi_{k}\right) \cap\left(\bigcap_{i=1}^{\infty} F\left(T_{i}\right)\right) \cap\left(\bigcap_{i=1}^{\infty} F\left(S_{i}\right)\right) \neq \emptyset$. Let $f: E \rightarrow \mathbb{R}$ be a convex and lower semicontinuous mapping with $C \subset \operatorname{int}(D(f))$, and suppose $\left\{x_{n}\right\}_{n=0}^{\infty}$ is iteratively generated by $x_{0} \in C$, $C_{1, i}=C, C_{1}=\bigcap_{i=1}^{\infty} C_{1, i}, x_{1}=\Pi_{C_{1}}^{f} x_{0}$,

$$
\begin{gathered}
z_{n, i}=J^{-1}\left(\beta_{n, i}^{(1)} J x_{n}+\beta_{n, i}^{(2)} J T_{i} x_{n}+\beta_{n, i}^{(3)} J S_{i} x_{n}\right), \\
y_{n, i}=J^{-1}\left(\alpha_{n, i} J x_{n}+\left(1-\alpha_{n, i}\right) J z_{n, i}\right), \\
u_{n, i}=T_{r_{m}, n}^{\varphi_{m}} T_{r_{m-1}, n}^{\varphi_{m-1}} \cdots T_{r_{2}, n}^{\varphi_{2}} T_{r_{1}, n}^{\varphi_{1}} y_{n, i}, \\
C_{n+1, i}=\left\{z \in C_{n, i}: G\left(z, J u_{n, i}\right) \leq G\left(z, J x_{n}\right)\right\}, \\
C_{n+1}=\bigcap_{i=1}^{\infty} C_{n+1, i}, \\
x_{n+1}=\Pi_{C_{n+1}}^{f} x_{0}, \quad n \geq 1,
\end{gathered}
$$

with the conditions 
(i) $\liminf \operatorname{in}_{n \rightarrow \infty} \beta_{n, i}^{(1)} \beta_{n, i}^{(2)}>0$,

(ii) $\liminf _{n \rightarrow \infty} \beta_{n, i}^{(1)} \beta_{n, i}^{(3)}>0$,

(iii) $0 \leq \alpha_{n, i} \leq \alpha<1$ for some $\alpha \in(0,1)$,

(iv) $\left\{r_{k, n}\right\}_{n=1}^{\infty} \subset(0, \infty)(k=1,2, \ldots, m)$ satisfying $\liminf _{n \rightarrow \infty} r_{k, n}>0(k=1,2, \ldots, m)$.

Then, $\left\{x_{n}\right\}_{n=0}^{\infty}$ converges strongly to $\Pi_{\Omega}^{f} x_{0}$.

\section{References}

[1] C. E. Chidume, Geometric Properties of Banach Spaces and Nonlinear Iterations, vol. 1965 of Lecture Notes in Mathematics, Springer, London, UK, 2009.

[2] W. Takahashi, Nonlinear Functional Analysis-Fixed Point Theory and Applications, Yokohama Publishers, Yokohama, Japan, 2000.

[3] W. Takahashi, Nonlinear Functional Analysis, Yokohama Publishers, Yokohama, Japan, 2000.

[4] D. Butnariu, S. Reich, and A. J. Zaslavski, "Asymptotic behavior of relatively nonexpansive operators in Banach spaces," Journal of Applied Analysis, vol. 7, no. 2, pp. 151-174, 2001.

[5] D. Butnariu, S. Reich, and A. J. Zaslavski, "Weak convergence of orbits of nonlinear operators in reflexive Banach spaces," Numerical Functional Analysis and Optimization, vol. 24, no. 5-6, pp. 489-508, 2003.

[6] Y. Censor and S. Reich, "Iterations of paracontractions and firmly nonexpansive operators with applications to feasibility and optimization," Optimization, vol. 37, no. 4, pp. 323-339, 1996.

[7] S. Matsushita and W. Takahashi, "A strong convergence theorem for relatively nonexpansive mappings in a Banach space," Journal of Approximation Theory, vol. 134, no. 2, pp. 257-266, 2005.

[8] X. Qin and Y. Su, "Strong convergence theorems for relatively nonexpansive mappings in a Banach space," Nonlinear Analysis, vol. 67, no. 6, pp. 1958-1965, 2007.

[9] W. Takahashi and K. Zembayashi, "Strong convergence theorem by a new hybrid method for equilibrium problems and relatively nonexpansive mappings," Fixed Point Theory and Applications, vol. 2008, Article ID 528476, 11 pages, 2008.

[10] W. Nilsrakoo and S. Saejung, "Strong convergence to common fixed points of countable relatively quasi-nonexpansive mappings," Fixed Point Theory and Applications, vol. 2008, Article ID 312454, 19 pages, 2008.

[11] X. Qin, Y. J. Cho, and S. M. Kang, "Convergence theorems of common elements for equilibrium problems and fixed point problems in Banach spaces," Journal of Computational and Applied Mathematics, vol. 225, no. 1, pp. 20-30, 2009.

[12] K. Wattanawitoon and P. Kumam, "Strong convergence theorems by a new hybrid projection algorithm for fixed point problems and equilibrium problems of two relatively quasi-nonexpansive mappings," Nonlinear Analysis: Hybrid Systems, vol. 3, no. 1, pp. 11-20, 2009.

[13] A. Chinchuluun, P. Pardalos, A. Migdalas, and L. Pitsoulis, Eds., Pareto optimality, Game Theory and Equilibria, vol. 17, Springer, New York, NY, USA, 2008.

[14] P. L. Combettes and S. A. Hirstoaga, "Equilibrium programming in Hilbert spaces," Journal of Nonlinear and Convex Analysis, vol. 6, no. 1, pp. 117-136, 2005.

[15] C. A. Floudas, A. Christodoulos, and P. M. Pardalos, Eds., Encyclopedia of Optimization, Springer, New York, NY, USA, 2nd edition, 2009.

[16] F. Giannessi, A. Maugeri, and P. M. Pardalos, Eds., Equilibrium Problems: Nonsmooth Optimization and Variational Inequality Models, vol. 58, Springer, New York, NY, USA, 2002.

[17] L. Lin, "System of generalized vector quasi-equilibrium problems with applications to fixed point theorems for a family of nonexpansive multivalued mappings," Journal of Global Optimization, vol. 34, no. 1, pp. 15-32, 2006.

[18] Y. Liu, "A general iterative method for equilibrium problems and strict pseudo-contractions in Hilbert spaces," Nonlinear Analysis, vol. 71, no. 10, pp. 4852-4861, 2009.

[19] A. Moudafi, "Weak convergence theorems for nonexpansive mappings and equilibrium problems," Journal of Nonlinear and Convex Analysis, vol. 9, no. 1, pp. 37-43, 2008.

[20] P. M. Pardalos, T. M. Rassias, and A. A. Khan, Eds., Nonlinear Analysis and Variational Problems, vol. 35 of Springer Optimization and Its Applications, Springer, New York, NY, USA, 2010. 
[21] S. Plubtieng and R. Punpaeng, "A new iterative method for equilibrium problems and fixed point problems of nonexpansive mappings and monotone mappings," Applied Mathematics and Computation, vol. 197, no. 2, pp. 548-558, 2008.

[22] X. Qin, M. Shang, and Y. Su, "Strong convergence of a general iterative algorithm for equilibrium problems and variational inequality problems," Mathematical and Computer Modelling, vol. 48, no. 7-8, pp. 1033-1046, 2008.

[23] Y. Su, M. Shang, and X. Qin, "An iterative method of solution for equilibrium and optimization problems," Nonlinear Analysis, vol. 69, no. 8, pp. 2709-2719, 2008.

[24] S. Takahashi and W. Takahashi, "Viscosity approximation methods for equilibrium problems and fixed point problems in Hilbert spaces," Journal of Mathematical Analysis and Applications, vol. 331, no. 1, pp. 506-515, 2007.

[25] R. Wangkeeree, "An extragradient approximation method for equilibrium problems and fixed point problems of a countable family of nonexpansive mappings," Journal of Fixed Point Theory and Applications, vol. 2008, Article ID 134148, 17 pages, 2008.

[26] E. Blum and W. Oettli, "From optimization and variational inequalities to equilibrium problems," The Mathematics Student, vol. 63, no. 1-4, pp. 123-145, 1994.

[27] S. Plubtieng and K. Ungchittrakool, "Strong convergence theorems for a common fixed point of two relatively nonexpansive mappings in a Banach space," Journal of Approximation Theory, vol. 149, no. 2, pp. 103-115, 2007.

[28] X. L. Qin, Y. J. Cho, S. M. Kang, and H. Y. Zhou, "Convergence of a hybrid projection algorithm in Banach spaces," Acta Applicandae Mathematicae, vol. 108, no. 2, pp. 299-313, 2009.

[29] X. Li, N. Huang, and D. O'Regan, "Strong convergence theorems for relatively nonexpansive mappings in Banach spaces with applications," Computers $\mathcal{E}$ Mathematics with Applications, vol. 60, no. 5, pp. 1322-1331, 2010.

[30] P. Cholamjiak and S. Suantai, "Convergence analysis for a system of equilibrium problems and a countable family of relatively quasi-nonexpansive mappings in Banach spaces," Abstract and Applied Analysis, vol. 2010, Article ID 141376, 17 pages, 2010.

[31] Y. I. Alber, "Metric and generalized projection operators in Banach spaces: properties and applications," in Theory and Applications of Nonlinear Operators of Accretive and Monotone Type, vol. 178 of Lecture Notes in Pure and Applied Mathematics, pp. 15-50, Dekker, New York, NY, USA, 1996.

[32] Y. I. Alber and S. Reich, "An iterative method for solving a class of nonlinear operator equations in Banach spaces," Panamerican Mathematical Journal, vol. 4, no. 2, pp. 39-54, 1994.

[33] I. Cioranescu, Geometry of Banach Spaces, Duality Mappings and Nonlinear Problems, vol. 62 of Mathematics and Its Applications, Kluwer Academic, Dordrecht, The Netherlands, 1990.

[34] S. Kamimura and W. Takahashi, "Strong convergence of a proximal-type algorithm in a Banach space," SIAM Journal on Optimization, vol. 13, no. 3, pp. 938-945, 2002.

[35] K. Q. Wu and N. J. Huang, "The generalised $f$-projection operator with an application," Bulletin of the Australian Mathematical Society, vol. 73, no. 2, pp. 307-317, 2006.

[36] J. Fan, X. Liu, and J. Li, "Iterative schemes for approximating solutions of generalized variational inequalities in Banach spaces," Nonlinear Analysis, vol. 70, no. 11, pp. 3997-4007, 2009.

[37] S. Chang, J. K. Kim, and X. R. Wang, "Modified block iterative algorithm for solving convex feasibility problems in Banach spaces," Journal of Inequalities and Applications, vol. 2010, Article ID 869684, 14 pages, 2010.

[38] Y. J. Cho, H. Zhou, and G. Guo, "Weak and strong convergence theorems for three-step iterations with errors for asymptotically nonexpansive mappings," Computers \& Mathematics with Applications, vol. 47, no. 4-5, pp. 707-717, 2004.

[39] W. Takahashi and K. Zembayashi, "Strong and weak convergence theorems for equilibrium problems and relatively nonexpansive mappings in Banach spaces," Nonlinear Analysis, vol. 70, no. 1, pp. 45-57, 2009. 


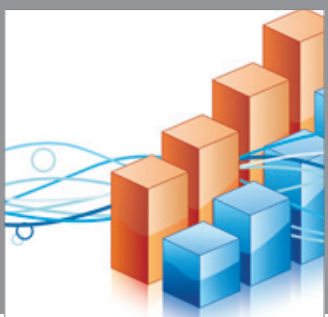

Advances in

Operations Research

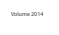

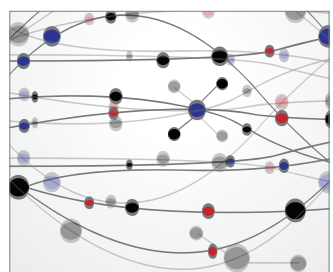

\section{The Scientific} World Journal
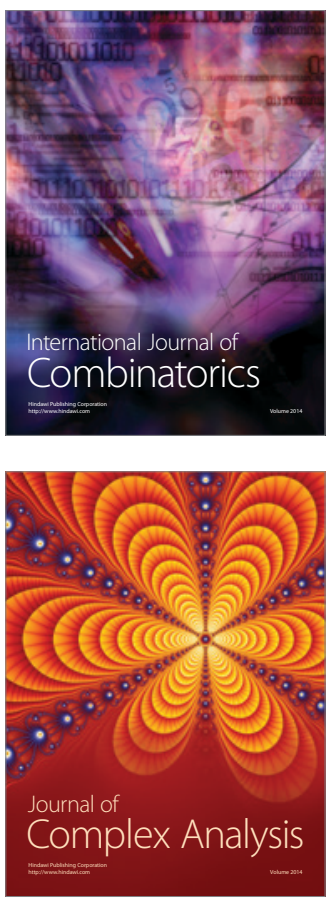

International Journal of

Mathematics and

Mathematical

Sciences
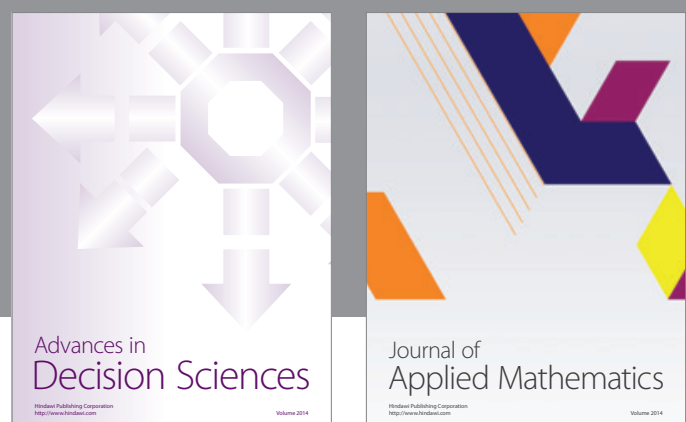

Journal of

Applied Mathematics
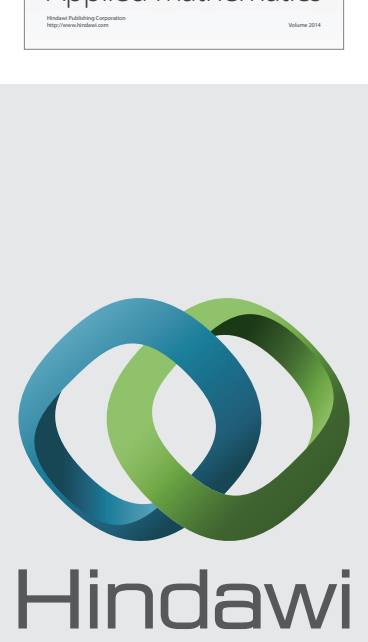

Submit your manuscripts at http://www.hindawi.com
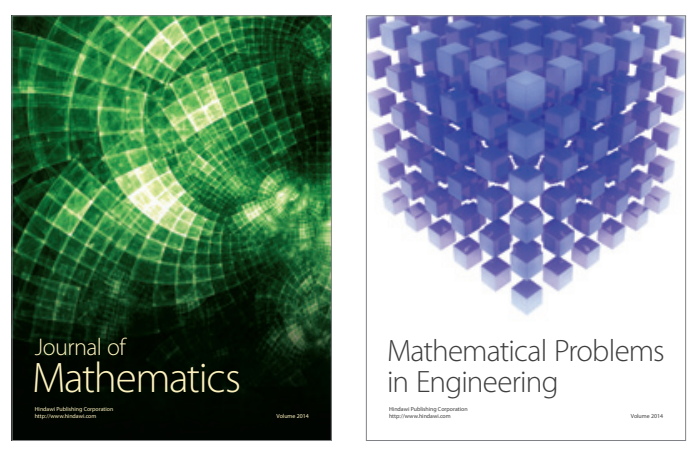

Mathematical Problems in Engineering
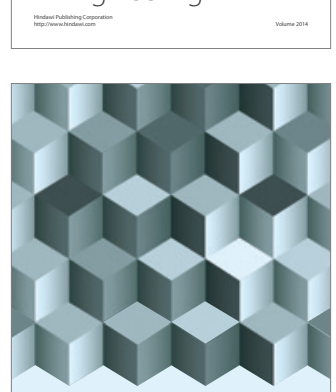

Journal of

Function Spaces
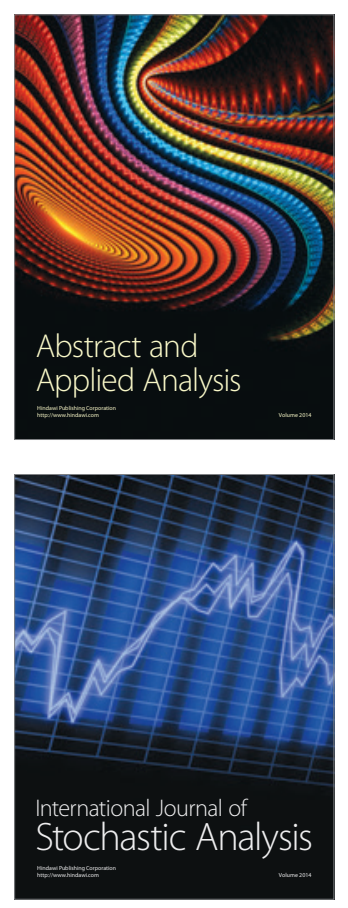

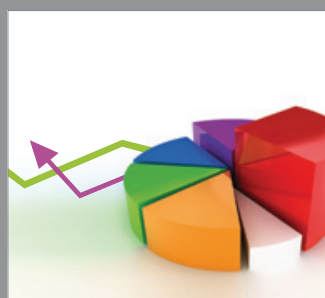

ournal of

Probability and Statistics

Promensencen
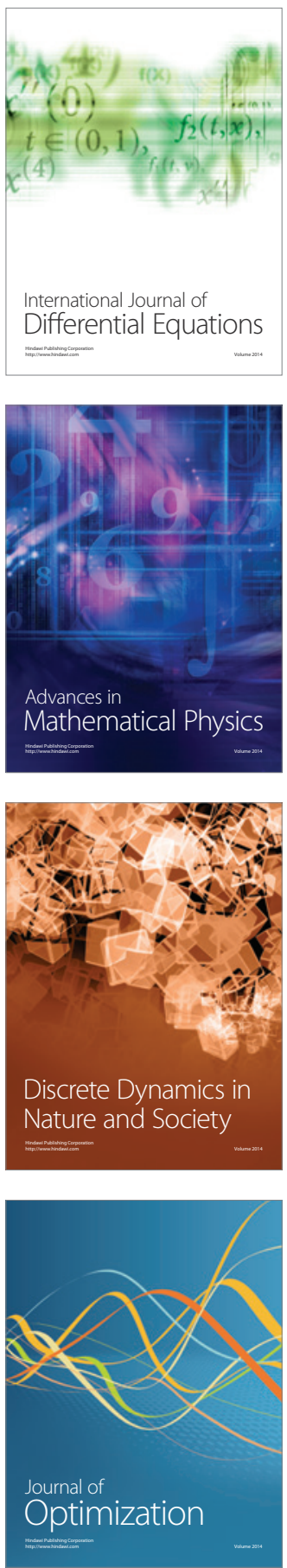